\title{
Childhood Asthma and Vitamin D-case Control Study in an Academic Tertiary Care Hospital
}

\author{
(1) Veena Anand, (1) Induprabha Yadev, (1) Bindusha Sasidharan \\ The Government Medical College Thiruvananthapuram, Department of Pediatrics, Kerala, India
}

\begin{abstract}
Aim: Vitamin D is suggested to be involved in the pathogenesis of childhood asthma. It is one of the most researched hypotheses but previous reports are inconclusive. The objective of this study was to investigate the association between vitamin D and asthma; and its association with level of control of asthma in children.
\end{abstract}

Materials and Methods: This case control study was conducted in a tertiary care teaching hospital among children of 6-12 years of age. Children with bronchial asthma who were under follow-up in a respiratory clinic were enrolled as the cases. Healthy children with no history of bronchial asthma were enrolled as the controls. Serum 25 hydroxyvitamin D was measured via a chemiluminescence method.

Results: There was high prevalence of vitamin D deficiency $(<20 \mathrm{ng} / \mathrm{mL})$ among children with asthma compared to control and was associated with occurrence of asthma $p=0.000$; Univariate analysis of the relationship between asthma and vitamin $D$ showed that decreased vitamin $D$ levels were associated with significantly increased odds of asthmatic state $(p<0.001)$. In multivariate analysis after adjustment for age, body mass index and sex, the relationship between vitamin D and asthma increased; but it was not associated with level of control of asthma.

Conclusion: There is high prevalence of vitamin D deficiency among children with asthma. Furthermore, the results did not consistently support that vitamin D levels associate with level of control of asthma.

Keywords: Asthma, child, prevalence, vitamin D

\section{Introduction}

Bronchial asthma is a heterogenous respiratory disease usually associated with hyper responsiveness and airway inflammation. Childhood asthma prevalence is increasing in developing countries despite improved knowledge of its pathophysiology and better management strategies (1). The development of asthma is associated with many immunological markers. There are upcoming reports on the potential link between vitamin $D$ and asthma. Increased asthma prevalence parallels the vitamin $D$ deficiency pandemic and adds to significant morbidity. The increased prevalence of asthma can be due to various genetic factors, environmental factors like urbanization or nutritional factors. Among the hypotheses related to nutritional factors, some current research focuses on the association of asthma with vitamin D deficiency. Vitamin $D$ is an immunomodulator involved in innate and acquired immunity $(2,3)$.

The association between vitamin D and bronchial asthma is not yet clear. Previous studies show a high prevalence of

\section{Address for Correspondence}

Veena Anand, The Government Medical College Thiruvananthapuram, Department of Pediatrics, Kerala, India Phone: 9447733969 E-mail: drveenaped@gmail.com ORCID: orcid.org/0000-0001-8472-0483 Received: 07.07.2020 Accepted: 28.09.2020

${ }^{(0)}$ Copyright 2021 by Ege University Faculty of Medicine, Department of Pediatrics and Ege Children's Foundation The Journal of Pediatric Research, published by Galenos Publishing House. 
vitamin D deficiency in childhood asthma (4-6) but some studies reported no difference in vitamin D levels $(7,8)$. Some studies even show that high levels of vitamin $D$ increase the risk of atopy (9). Recent metanalysis show mixed results for the association of vitamin D with asthma (3). Prevalence of vitamin D deficiency varies according to geographical location, latitude, or population studied. High prevalence has been reported even in sun replete areas. Factors like urbanization, genetic factors, decreased outdoor activities, decreased sun exposure, low physical activity, obesity, or deficient diet can lead to an increased prevalence of vitamin $D$ deficiency. Additionally, the reported prevalence varies according to varying cut-off levels for defining deficiency, different methods for vitamin $D$ estimation and the season of vitamin D estimation (10). Country wide reports show conflicting results on the prevalence of vitamin D deficiency in asthma; especially those from Asian countries (11). Racial/ ethnic-specific associations between vitamin D insufficiency and asthma in children is also reported (12). Vitamin D receptor gene polymorphism has been associated with asthma phenotypes (2). There are studies which reported the effects of prenatal vitamin D exposure (13-18). Hollams (19) in a cohort study reported low vitamin D at 6 years is a predictor of asthma at 14 years of age. Van Oeffelen et al. (20) reported serum vitamin D measured at age 4 is inversely associated with asthma at 4-8 years whereas vitamin D measured at age 8 is positively associated with asthma. Randomized controlled trials give inconclusive reports on vitamin D supplementation (21). Rapid correction of very low vitamin levels shows short-term benefits but no long-term effects (22). The threshold level of vitamin D level to be maintained in asthma is unknown. Available evidence does not confirm or rule out the benefits of vitamin $D$ supplementation and, if found useful, would be a cheaper alternative with less side effects.

With childhood asthma being highly prevalent and with its significant morbidity, it is important to know its association with vitamin $\mathrm{D}$. There is a scarcity of literature from Asian countries, and these have conflicting reports. This may be due to variations in geographical location and populations studied. Therefore, it is important to know the situation in our area, which is a tropical region. The objective of the present study was to investigate the association of vitamin $D$ in children with asthma compared to normal children in our region and to determine whether vitamin $D$ status is related to the level of control of asthma.

\section{Materials and Methods}

This case control study was conducted in an academic tertiary care hospital. Cases were recruited from the pediatric respiratory clinic of our institution. All consecutive cases of respiratory physician diagnosed asthma in the age group of 6-12 years with good compliance when they came for follow-up in the respiratory clinic were recruited as cases. Children with acute illness, chronic diseases like heart disease, neurological disease, diseases which affect vitamin $D$ metabolism such as liver disease, renal disease, a history of vitamin D supplementation in the previous 6 months, or on drugs that affect vitamin D supplementation such as anticonvulsants were excluded. The controls were recruited from 6-12-year-old healthy children with no history of bronchial asthma with exclusion criteria similar to that of the cases, coming to immunization clinic/follow-up in out-patient clinic. Written informed parental consent or assent from all participants were obtained wherever necessary. Approval of the institutional ethics committee was obtained.

Parents and children were interviewed to collect data regarding age, sex, weight, height, body mass index (BMI), average sun exposure duration between 10 a.m.-3 p.m., average outdoor physical activity in the previous month and asthma control status in those with history of asthma. The Indian Academy of Pediatrics growth chart was used for height, weight and BMI cut-off levels. Those with sun exposure during 10 a.m. to 3 p.m. of at least 6 hours per week were considered as having adequate sun exposure. Physical activity of at least 1 hour daily was considered as adequate. Venous blood was collected and Serum 25 hydroxyvitamin $D[25(\mathrm{OH}) \mathrm{D}]$ estimation was done in all cases and controls using the chemiluminescence method. A vitamin D level $<20 \mathrm{ng} / \mathrm{mL}$ was considered deficient (11). According to Global Initiative for Asthma (GINA) guidelines, children with asthma were grouped into 3 groups according to their level of control of asthma (1).

\section{Statistical Analysis}

Statistical analysis was carried out using $R$ statistical software version 3.0. Univariate analysis was performed to assess the distribution of baseline variables. In a multiple logisticregression model, analyseswereadjustedforpotential confounding by age, sex, BMI, adequate physical activity and sun exposure. The results are presented as frequencies (number) and percentages for categorical variables (nonparametric data) and mean \pm standard deviation (SD) for continuous variables (parametric data) and median and interquartile range (IQR) for non-parametric variables. The statistical tests, chi-square test $\left(\chi^{2}\right)$ for categorical variables, independent sample t-test, Mann-Whitney $U$ test, One-Way ANOVA and Kruskal-Wallis tests for continuous 
variables were used for analysis. The odds ratio (OR) with a 95\% confidence interval was also calculated to assess the association of variables with vitamin $D$ deficiency. P-values of the likelihood ratio tests were used to test for statistical significance in logistic regression analyses. All p-values are two-tailed, and statistical significance was defined as $\mathrm{p}<0.05$.

\section{Results}

Out of 193 participants, there were 101 cases of asthma and 92 controls. The median (IQR) vitamin D level was 20.76 $(15,31) \mathrm{ng} / \mathrm{mL}$. The median (IQR) age was $8.5(7,11)$ years. There were 113 (58.5\%) male children. Mean (SD) height was $129.6 \mathrm{~cm}$ (14) with 184 (95.3\%) children in the normal range. Mean (SD) weight was $27 \mathrm{~kg}$ (9.8) among which 10 (5.2\%) were underweight, 181 (93.8\%) were normal and 2 (1\%) were overweight. Mean (SD) BMI was 15.6 (3.6), out of which 32 (16.6\%) were thin, 112 (58\%) were normal, 31 $(16 \%)$ were overweight and $18(9.3 \%)$ were obese. There was adequate sun exposure for only 66 (34\%) children. There was adequate physical activity for 119 (61\%) children with mean physically active hours per week of 8.41 (4.63) hour. The measured vitamin D levels stratified according to month of examination did not show much variation as shown in Figure 1.

Vitamin D deficiency was seen in 88 (45.6\%) children. Median (IQR/age was $8(7,10)$ in those with vitamin D sufficiency and $9(7,11)$ in those with deficiency. Among children with vitamin D sufficiency 65 (61.9\%) were males and among those with deficiency 48 (54.5\%) were males.

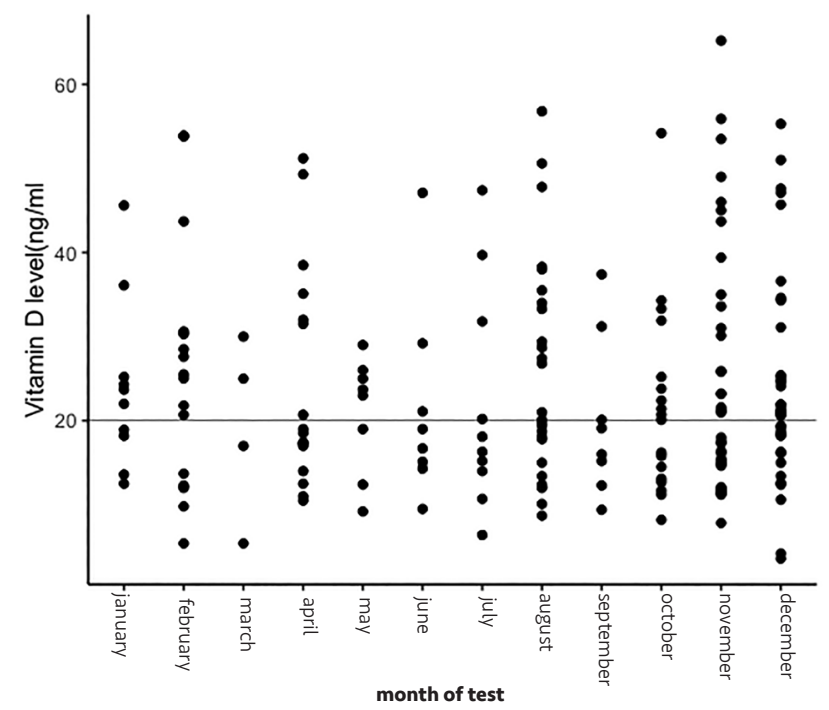

Figure 1. Scatter diagram showing vitamin $D$ levels $(\mathrm{ng} / \mathrm{mL})$ and month of test
Mean (SD) BMI was 15.4 (3) $\mathrm{kg} / \mathrm{m}^{2}$ among children with vitamin D deficiency and 15.8 (3.9) $\mathrm{kg} / \mathrm{m}^{2}$ among those with sufficiency. Adequate sun exposure was seen in 33 (31.4\%) and $33(37.5 \%)$ in the vitamin D sufficient and deficient groups respectively. Physical activity was adequate in 68 (64.8\%) and 51 (58\%) in the sufficient and deficient groups with mean (SD) active hours per week 8.49 (4.4) and 8.31 (4.9) respectively. Mean (SD) height was 130 (14.5) cm in the vitamin D deficient and $129(13.6) \mathrm{cm}$ in sufficient groups. Mean (SD) weight was 26.8 (9) kg in the deficient and 27 (10.26) kg in sufficient groups. Height was normal in 101 (96.2\%) sufficient and 83 (94.3\%) deficient groups and weight was normal in 98 (93.3\%) and 83 (94.3\%).

Characteristics of both asthma cases and controls and the differences between the two groups are shown in Table I. Median vitamin D levels in the cases and controls were 17.30 $\mathrm{ng} / \mathrm{mL}$ and $30.45 \mathrm{ng} / \mathrm{mL}$ respectively; this difference was statistically significant $(p<0.001)$. Also, vitamin deficiency was significantly associated with asthma cases $(p<0.001)$. Adequate physical activity was significantly high, and BMI was significantly lower in the asthma cases.

Among the 101 children with asthma, 65 (64.3\%) children had vitamin D deficiency. However, among the controls only $23(25 \%)$ had deficiency. Vitamin D deficiency was associated with the occurrence of asthma $(p=0.000)$ (Figure 2). However, the level of control of asthma and vitamin $D$ deficiency did not show any significant association (Table II).

Univariate analysis of the relationship between asthma showed that decreased vitamin D levels were associated with significantly increased odds of asthmatic state $(p<0.001)$. Multivariate analyses of the relationship between asthma and vitamin D levels with adjustment for age, sex, BMI, adequate physical activity and sun exposure were conducted. As shown in Table III, a significant relationship between vitamin $D$ levels and asthma can be seen in multivariate

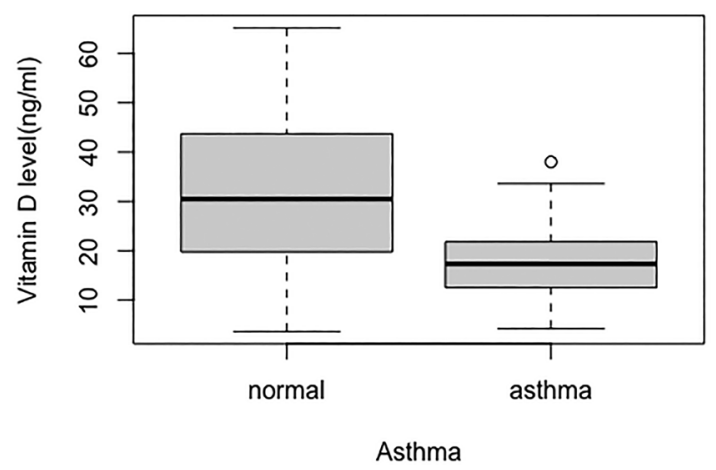

Figure 2. Boxplot showing association between vitamin D levels and asthma 


\begin{tabular}{|c|c|c|c|}
\hline & Asthma $(n=101)(\%)$ & Controls $(n=92)(\%)$ & p-value \\
\hline Age in year [median (IQR)] & $8(6,11)$ & $9.00(7,10)$ & $0.288^{*}$ \\
\hline Gender-male & $62(61.4)$ & $51(55.4)$ & $0.489 * *$ \\
\hline $\begin{array}{l}\text { Weight [median (IQR)] } \\
\text { - Underweight } \\
\text { - Normal } \\
\text { - Overweight }\end{array}$ & $\begin{array}{l}24(18.31) \\
9(8.9) \\
92(91.1) \\
9(8.9)\end{array}$ & $\begin{array}{l}27.5(20.35) \\
1(1.1) \\
89(96.7) \\
2(2.2) \\
\end{array}$ & $\begin{array}{l}0.032^{*} \\
0.018^{* *}\end{array}$ \\
\hline $\begin{array}{l}\text { Height [median (IQR)] } \\
\text { - Normal }\end{array}$ & $\begin{array}{l}128(114.141) \\
94(93.1)\end{array}$ & $\begin{array}{l}130.5(121.138) \\
90(97.8)\end{array}$ & $\begin{array}{l}0.231^{*} \\
0.221^{* *}\end{array}$ \\
\hline $\begin{array}{l}\text { BMI [median (IQR)] } \\
\text { - Thinness } \\
\text { - Normal } \\
\text { - Overweight } \\
\text { - Obese }\end{array}$ & $\begin{array}{l}14.3(13,16) \\
17(16.8) \\
70(69.3) \\
9(8.9) \\
5(5) \\
\end{array}$ & $\begin{array}{l}14.6(13.19) \\
15(16.3) \\
42(45.7) \\
22(23.9) \\
13(14.1) \\
\end{array}$ & $\begin{array}{l}0.057^{*} \\
0.001^{* *}\end{array}$ \\
\hline Adequate sun exposure & $39(38.6)$ & $27(29.3)$ & $0.229^{*}$ \\
\hline $\begin{array}{l}\text { Physical activity } \\
\text { - Total hr/week-mean (SD) } \\
\text { - Adequate }\end{array}$ & $\begin{array}{l}9.69(5.14) \\
72(71.3)\end{array}$ & $\begin{array}{l}6.99(3.5) \\
47(51.1)\end{array}$ & $\begin{array}{l}<0.001^{* * *} \\
0.006^{* *}\end{array}$ \\
\hline $\begin{array}{l}\text { Vitamin D } \\
\text { - Level (ng/mL) [median (IQR)] } \\
\text { - Deficiency }\end{array}$ & $\begin{array}{l}17.3(12.22) \\
65(64.4)\end{array}$ & $\begin{array}{l}30(19,43) \\
23(25)\end{array}$ & $\begin{array}{l}<0.001^{*} \\
<0.001^{* *}\end{array}$ \\
\hline
\end{tabular}

Table II. Characteristics of asthma cases according to level of control of asthma

\begin{tabular}{|c|c|c|c|c|}
\hline & Well controlled (\%) & Partly controlled (\%) & Uncontrolled (\%) & p-value \\
\hline Age in year [median (IQR)] & $8(6,10.5)$ & $8.5(6,10.8)$ & $9(6,11.5)$ & $0.809^{* *}$ \\
\hline Gender-male & $25(62.5)$ & $23(60.5)$ & $14(60.9)$ & $0.982^{* * *}$ \\
\hline $\begin{array}{l}\text { Weight [median (IQR)] } \\
\text { - Underweight } \\
\text { - Normal }\end{array}$ & $\begin{array}{l}20(17.29) \\
4(10) \\
39(90)\end{array}$ & $\begin{array}{l}25(20.32) \\
2(5) \\
36(90)\end{array}$ & $\begin{array}{l}25(17.30) \\
3(13) \\
20(87)\end{array}$ & $0.237^{* *}$ \\
\hline $\begin{array}{l}\text { Height [median (IQR)] } \\
\text { Normal }\end{array}$ & $\begin{array}{l}121(114.136) \\
38(95)\end{array}$ & $\begin{array}{l}128(118.139) \\
36(94)\end{array}$ & $\begin{array}{l}131(113,141) \\
20(87)\end{array}$ & $\begin{array}{l}0.699^{* *} \\
0.422^{* * *}\end{array}$ \\
\hline $\begin{array}{l}\text { BMI [median (IQR)] } \\
\text { - Thinness } \\
\text { - Normal } \\
\text { - Overweight } \\
\text { - Obese }\end{array}$ & $\begin{array}{l}13.8(13.15) \\
5(12.5) \\
33(82.5) \\
2(5) \\
0(0)\end{array}$ & $\begin{array}{l}15.5(14.17) \\
6(16) \\
23(60) \\
5(13) \\
4(10)\end{array}$ & $\begin{array}{l}14.5(13.16) \\
6(26) \\
14(60) \\
2(8.7) \\
1(4.3)\end{array}$ & $\begin{array}{l}0.076^{* *} \\
0.166^{* * *}\end{array}$ \\
\hline Adequate sun exposure & $16(40)$ & $17(44)$ & $6(26)$ & $0.340^{* * *}$ \\
\hline $\begin{array}{l}\text { Physical activity } \\
\text { - Total hour per week-mean (SD) } \\
\text { - Adequate }\end{array}$ & $\begin{array}{l}10(4.7) \\
29(72) \\
\end{array}$ & $\begin{array}{l}9.5(5.9) \\
26(68)\end{array}$ & $\begin{array}{l}8.6(4.3) \\
17(73.9) \\
\end{array}$ & $\begin{array}{l}0.399^{*} \\
0.879^{* * *}\end{array}$ \\
\hline Vitamin D deficiency & $25(62.5)$ & $29(76.3)$ & $11(47.8)$ & $0.075^{* * *}$ \\
\hline
\end{tabular}




\begin{tabular}{|c|c|c|c|c|}
\hline Variable & Univariate OR $(95 \% \mathrm{Cl})$ & p-value & Multivariate OR $(95 \% \mathrm{CI})$ & p-value \\
\hline Age & $0.94(0.82-1.07)$ & 0.333 & $0.99(0.83-1.19)$ & 0.939 \\
\hline Gender & $1.28(0.72-2.27)$ & 0.402 & $1.31(0.62-2.77)$ & 0.481 \\
\hline BMI & $0.88(0.81-0.96)$ & 0.005 & $0.86(0.76-0.97)$ & 0.017 \\
\hline Vitamin D & $0.89(0.85-0.92)$ & $<0.001$ & $0.87(0.83-0.91)$ & $<0.001$ \\
\hline Sun exposure & $1.51(0.83-2.78)$ & 0.176 & $1.09(0.49-2.45)$ & 0.825 \\
\hline Physical activity & $1.15(1.07-1.23)$ & $<0.001$ & 1.19 (1.09-1.31) & $<0.001$ \\
\hline Weight & $0.97(0.94-1.00)$ & 0.057 & - & - \\
\hline Height & $0.99(0.97-1.01)$ & 0.327 & - & - \\
\hline
\end{tabular}

analysis. Increased vitamin D levels were associated with a greater decrease in the probability $(p<0.001)$ of asthma compared with univariate analysis (OR 0.89 and 0.87).

\section{Discussion}

Vitamin D deficiency is common and was seen in half of our study participants similar to other hospital-based studies $(6,23)$. However, another study showed higher prevalence but their population area constituted urban and semirural areas (22). One quarter of normal children had vitamin $D$ deficiency in spite of our region being a tropical region receiving substantial amounts of sunlight. The median serum vitamin D level was $20.76 \mathrm{ng} / \mathrm{mL}$. There was adequate average daily sun exposure for only one third of the children, but it did not differ significantly between the sufficient and deficient groups. The month of test of vitamin $D$ did not show much variation in vitamin D levels which in turn shows that seasonal variation is not significant. Other factors like skin color, clothing, genetic or dietary factors can affect vitamin D levels. In order to determine the exact prevalence of vitamin D deficiency, populationbased studies are required. As our study was a hospitalbased study, from our data, we cannot suggest screening of normal children for subclinical vitamin D deficiency.

The vitamin $\mathrm{D}$ deficient and sufficient groups did not differ much by age, sex, height, weight, BMI, adequate sun exposure or physical activity. Even though dietary factors contribute to only $10-15 \%$ of vitamin D level, supplementation or food fortification may be considered for subclinical vitamin $D$ deficiency because of its crucial role during the growing age.

An increased prevalence of vitamin D deficiency $(<20$ $\mathrm{ng} / \mathrm{mL}$ ) is seen in children with asthma and it is statistically significant. Two thirds of asthma cases had vitamin D deficiency compared to only one fourth of the controls. Similar results are reported by other Indian studies. Awasthi and Vikram (6) reported vitamin D insufficiency (<30 ng/ $\mathrm{mL}$ ) in $84 \%$ of asthma cases and $28 \%$ of controls. Median vitamin $\mathrm{D}$ level was low in the asthma group compared to the controls. Two of the proposed reasons for low vitamin $D$ levels in asthma patients are decreased sun exposure and restricted physical activity. However, in our study, adequate sun exposure and physical activity were significantly more in the asthma group. We conducted univariate analysis and found a strong inverse association between serum vitamin D levels and asthma. In the multivariate analysis, after adjusting for age, sex, BMI, sun exposure and physical activity, this relationship increased compared to the univariate analysis ( $O R=0.89-0.87)$. It confirms the association between lower vitamin $\mathrm{D}$ levels and asthma.

An explanation for the potential association between vitamin $\mathrm{D}$ and the development of asthma is that adequate vitamin D levels during pregnancy and early childhood prevent respiratory infections, help lung development, and thus decrease asthma risk (18). Vitamin D deficiency affects the development of immune tolerance and the epithelial barrier function in early childhood and thus relates to the development of asthma $(18,19)$. Vitamin D has a major role in immune homeostasis. The vitamin $D$ receptor is associated with the transcription of genes related to inflammation and immunomodulation of respiratory epithelium which is a part of the innate immune system and contains a high level of the enzyme which converts 25(OH)D3 to its active form. This active form of vitamin $D$ has a local effect on infection responses and is effective in alleviating inflammation due to infections. Also, through direct induction of antimicrobial peptide gene expression, it is involved in innate immunity. Vitamin D also affects the adaptive immune system through 
Th1, Th2 and regulatory T-cells. Vitamin D activates antiinflammatory cytokines and inhibits proinflammatory cytokines. Vitamin D shifts T-lymphocyte response between Th1 phenotype and Th2 (3). The reason for low vitamin $D$ levels in asthma may be due to increased demand due to excessive consumption in asthma with recurrent inflammation and so higher amounts may be required for immune functions. However, there is no consensus for the optimal serum levels to be maintained in asthma.

Asthma guidelines focus on the attainment of asthma control. However, there is no single measure to assess asthma control. Our study has not found any association between vitamin $\mathrm{D}$ deficiency and the level of control of asthma. Previous studies report an inconsistent association between the level of control of asthma and vitamin D levels; different studies used different methods to assess the level of control and different cut-off points for vitamin D deficiency. Kavitha et al. (24) did not identify any significant relationship between vitamin $\mathrm{D}$ levels and asthma control according to GINA in children aged 5-15 years but a study conducted by Kaaviya et al. (25) identified a significant relationship between vitamin $D$ levels and asthma control according to GINA in children aged 5-15 years. A case control study conducted by Awasthi and Vikram (6) showed poorer asthma control associated with decreasing vitamin D levels in children aged 1-15 years. A study carried out in Thailand by Krobtrakulchai et al. (26) in 125 asthmatic children showed no association between vitamin D levels. Gupta et al. (27) conducted a study that assessed the control of asthma with the Asthma Control Test and found that lower vitamin D levels were associated with poor asthma control. Recent trials in children and adults with asthma revealed an inconsistent effect of vitamin $D$ supplementation on symptom control (28-31).

\section{Study Limitations}

High serum parathyroid hormone level is the true indicator of vitamin D deficiency. It was not measured in this study. Longitudinal studies are required to prove the causeeffect relationship of vitamin $D$ levels and asthma and interventional studies are needed to investigate the effect of vitamin D supplementation on asthma. We assessed the level of control of asthma using GINA symptom control history for the period of the previous 4 weeks only. A study which takes into consideration different methods to assess the level of control of asthma with a sufficient sample in all groups of the levels of control is required to assess this association. Studies focusing on vitamin D level variations and asthma parameters, which may depend on the genotype or phenotype of children with asthma, are needed to clarify the effect of vitamin D status on asthma.

\section{Conclusion}

Vitamin D deficiency is prevalent in children with asthma in the present setting. There was no significant association between serum vitamin $D$ levels and asthma control status.

Ethics

Ethics Committee Approval: Approval of the institutional ethics committee was obtained (IEC no: 08/26/2017/MCT, date: 28/07/2017).

Informed Consent: Written informed parental consent or assent from all participants were obtained wherever necessary.

Peer-review: Internally and externally peer-reviewed.

\section{Authorship Contributions}

Concept: V.A., I.Y., B.S., Design: V.A., I.Y., B.S., Data Collection or Processing: V.A., I.Y., B.S., Analysis or Interpretation: V.A., I.Y., B.S., Literature Search: V.A., I.Y., B.S., Writing: V.A., I.Y., B.S.

Conflict of Interest: No conflict of interest was declared by the authors.

Financial Disclosure: The authors declared that this study received no financial support.

\section{References}

1. The Global Initiative for Asthma. GINA Report, Global Strategy for Asthma Management and Prevention. Fontana, WI, USA: The Global Initiative for Asthma; 2020. Available from: http:// ginasthma.org/

2. Kilic M, Ecin S, Taskin E, Sen A, Kara M. The Vitamin D receptor gene polymorphisms in asthmatic children: a case-control study. Pediatr Allergy Immunol Pulmonol 2019; 32:63-9.

3. lat KR, Khairwa A. Vitamin D and asthma in children: A systematic review and meta-analysis of observational studies. Lung India 2017; 34:355-63.

4. Ahmed AE, Hassan MH, Toghan R, Rashwan NI. Analysis of 25-hydroxy cholecalciferol, immunoglobulin $E$, and vitamin $D$ receptor single nucleotide polymorphisms (Apa1, Taq1, and Bsm1), among sample of Egyptian children with bronchial asthma: A case-control study. Pediatr Pulmonol 2020; 55:134958.

5. Kim YR, Seo SC, Yoo Y, Choung JT. Are children with asthma in South Korea also associated with vitamin D deficiency? Environ Health Toxicol 2017; 32:e2017005. doi: 10.5620/eht.e2017005.

6. Awasthi S, Vikram K. Serum 25 hydroxy vitamin D insufficiency associated with bronchial asthma in Lucknow, India. Indian I Pediatr 2014; 81:644-9.

7. Dogru M, Kirmizibekmez H, Yesiltepe Mutlu RG, Aktas A, Ozturkmen S. Clinical effects of vitamin D in children with asthma. Int Arch Allergy Immunol 2014; 164:319-25. 
8. Dabbah H, Bar Yoseph R, Livnat G, Hakim F, Bentur L. Bronchial reactivity, inflammatory and allergic parameters, and vitamin $d$ levels in children with asthma. Respir Care 2015; 60:1157-63.

9. Gale $C R$, Robinson $S M$, Harvey NC, et al. Maternal vitamin $D$ status during pregnancy and child outcomes. Eur J Clin Nutr 2008; 62:68-77.

10. Amrein $K$, Scherkl M, Hoffmann $M$, et al. Vitamin D deficiency 2.0: an update on the current status worldwide. Eur J Clin Nutr $2020 ; 74: 1498-513$.

11. Man $L$, Zhang Z, Zhang $M$, et al. Association between vitamin $D$ deficiency and insufficiency and the risk of childhood asthma: evidence from a meta-analysis. Int I Clin Exp Med 2015; 8:5699706.

12. Han YY, Forno E, Celedón JC. Vitamin D Insufficiency and asthma in a us nationwide study. I Allergy Clin Immunol Pract 2017; 5:790-6.

13. Mirzakhani $\mathrm{H}$, Carey V), Zeiger R, et al. Impact of parental asthma, prenatal maternal asthma control, and vitamin $D$ status on risk of asthma and recurrent wheeze in 3-year-old children. Clin Exp Allergy 2019; 49:419-29.

14. Allan KM, Prabhu N, Craig LC, et al. Maternal vitamin D and E intakes during pregnancy are associated with asthma in children. Eur Respir / 2015; 45:1027-36.

15. Camargo CA Jr, Rifas-Shiman SL, Litonjua AA, et al. Maternal intake of vitamin $D$ during pregnancy and risk of recurrent wheeze in children at 3 y of age. Am J Clin Nutr 2007; 85:788-95.

16. Devereux G, Litonjua AA, Turner SW, et al. Maternal vitamin D intake during pregnancy and early childhood wheezing. Am J Clin Nutr 2007; 85:853-9.

17. Erkkola M, Kaila M, Nwaru Bl, et al. Maternal vitamin D intake during pregnancy is inversely associated with asthma and allergic rhinitis in 5-year-old children. Clin Exp Allergy 2009; 39:875-82.

18. Bozzetto S, Carraro S, Giordano G, Boner A, Baraldi E. Asthma, allergy and respiratory infections: the vitamin $D$ hypothesis. Allergy 2012; 67:10-7.

19. Hollams EM. Vitamin D and atopy and asthma phenotypes in children. Curr Opin Allergy Clin Immunol 2012; 12:228-34.

20. Van Oeffelen AA, Bekkers MB, Smit HA, et al. Serum micronutrient concentrations and childhood asthma: the
PIAMA birth cohort study. Pediatr Allergy Immunol 2011; 22:78493.

21. Kang Q, Zhang X, Liu S, Huang F. Correlation between the vitamin $D$ levels and asthma attacks in children: Evaluation of the effects of combination therapy of atomization inhalation of budesonide, albuterol and vitamin $D$ supplementation on asthmatic patients. Exp Ther Med 2018; 15:727-32.

22. Harinarayan CV, Ramalakshmi T, Prasad UV, Sudhakar D. Vitamin D status in Andhra Pradesh: a population based study. Indian I Med Res 2008; 127:211-8.

23. Bindusha S, Riaz I, Sujith KR, Kailas L. The Vitamin D Status in 6-14 Year Old Children Attending Tertiary Care Teaching Hospital in South India. Int J Cur Res Rev 2017; 9:53-8.

24. Kavitha TK, Gupta N, Kabra SK, Lodha R. Association of serum vitamin $D$ levels with level of control of childhood asthma. Indian Pediatr 2017; 54:29-32.

25. Kaaviyaa AT, Krishna V, Arunprasath TS, Ramanan PV. Vitamin $D$ deficiency as a factor influencing asthma control in children. Indian Pediatr 2018; 55:969-71.

26. Krobtrakulchai W, Praikanahok J, Visitsunthorn N, et al. The effect of vitamin d status on pediatric asthma at a university hospital, Thailand. Allergy Asthma Immunol Res 2013; 5:28994.

27. Gupta A, Sjoukes A, Richards D, et al. Relationship between serum vitamin $D$, disease severity, and airway remodeling in children with asthma. Am J Respir Crit Care Med 2011; 184:13429.

28. Lewis E, Fernandez C, Nella A, Hopp R, Gallagher JC, Casale TB. Relationship of 25-hydroxyvitamin $\mathrm{D}$ and asthma control in children. Ann Allergy Asthma Immunol 2012; 108:281-2.

29. Bar Yoseph R, Livnat G, Schnapp Z, et al. The effect of vitamin D on airway reactivity and inflammation in asthmatic children: $A$ double-blind placebo-controlled trial. Pediatr Pulmonol 2015; 50:747-53

30. Jensen $M E$, Mailhot $G$, Alos $N$, et al. Vitamin $D$ intervention in preschoolers with viral-induced asthma (DIVA): a pilot randomised controlled trial. Trials 2016; 17:353.

31. Martineau AR, Cates C), Urashima $M$, et al. Vitamin D for the management of asthma. Cochrane Database Syst Rev 2016; 9:CD011511. doi: 10.1002/14651858.CD011511.pub2. 